\title{
Learned and perceived reinforcer response strengths and image theory
}

\author{
DONALD L. KING \\ Howard University, Washington, D. C. 20059
}

\begin{abstract}
The main purposes are to (a) indicate that $\mathrm{CR}$ and instrumental response strengths are related to response strengths to perceived reinforcers establishing these learned responses, and (b) suggest that learned responses may result, in part, from images of reinforcers, because image-produced behavior is related to stimulus-produced behavior, analogous to learned response strength being related to perceived reinforcer response strength. In addition, that image-produced behavior is related to stimulus-produced behavior is supported, and specific ways in which image-produced behavior may contribute to classical and instrumental conditioning are touched on.
\end{abstract}

More intense UCSs elicit stronger GSR and eyelid movement UCRs as well as establish stronger GSR and eyelid movement CRs (Öhman, Björkstrand, \& Ellström, 1973; Sheafor \& Gormezano, 1972). It will therefore be suggested that variation in amount and intensity of the UCS results in a positive relation between CR strength and UCR strength.

The strengths of salivation, mouth licking, and jaw movement CRs and UCRs increased with an increase in deprivation of food or water (DeBold, Miller, \& Jensen, 1965; Finch, 1938; Mitchell \& Gormezano, 1970). It therefore seems that variation in deprivation level results in a positive relation between $\mathrm{CR}$ strength and UCR strength.

That a positive relation between $\mathrm{CR}$ strength and UCR strength exists is further supported by studies suggesting that decreasing UCR strength by habituation to a UCS or by pairing a positive UCS with a negative reinforcer also decreases CR strength. Taylor (1956) found that repeated presentations of a puff of air to the eye decreased the amplitude of the eyelid movement response and also the number of eyelid movement CRs. Rescorla (1973) found that habituation to the UCS of a loud noise decreased the strength of a suppression CR. Holland and Rescorla (1975) found that pairing food with rotation decreased food consumption and also decreased the strength of an activity $\mathrm{CR}$ established with CS-food pairings.

Because CR strength and UCR strength co-vary in the ways indicated above, it - will be concluded that, in general, CR strength is quantitatively related in a correlational sense with UCR strength.

Although the statement that CR strength is quantitatively related to UCR strength is not surprising, it does not appear to have been frequently supported and discussed. Of the previously mentioned papers, discussion

Send requests for reprints to Donald L. King, Department of Psychology, Howard University, Washington. D.C. 20059. by DeBold et al. bears on the indicated statement. They mention that their own result is in accord with Pavlov's comment (1927, pp. 31-32) implying that deprivation level affects both the strengths of the salivation $C R$ and UCR. However, DeBold et al. did not link up the effect of deprivation on CR and UCR strength with the effect of amount and intensity of reinforcement on $C R$ and UCR strength.

\section{PREMACK'S WORK AND RESPONSE TO PERCEIVED REINFORCER}

Premack's work suggests that the strength of the instrumental response is related to the strength of the response to the perceived stimulus the instrumental response causes to occur. For ease of exposition, for the remainder of this paper only reward learning will be discussed, and therefore the stimulus following the instrumental response will be considered to be a positive reinforcer.

Two illustrative results of Premack will be described, one pertaining to amount of reinforcement and the other to deprivation of reinforcement. Premack (1963) measured the proportion of time rats drank sucrose solutions of different concentrations. Delivery of a sucrose solution of a particular concentration was then made contingent on the occurrence of barpressing. The strength of barpressing increased with the proportion of time a particular concentration of sucrose solution was drunk. In another study (Premack, 1965), for one condition rats had free access to water but only limited access to an activity wheel. It was found for this condition that the proportion of time rats spent drinking was less than the proportion of time rats spent running. In addition, when access to water was made contingent on running in the wheel, the strength of running did not increase. But when access to the wheel was made contingent on drinking, the strength of drinking increased. In a second condition rats were deprived of water. It was 
found for this condition that rats spent a greater proportion of time drinking than running in the activity wheel. In addition, when access to water was made contingent on running in the wheel, the strength of running increased; when access to the wheel was made contingent on drinking, the strength of drinking did not increase.

In these studies, the proportion of time animals spent drinking sucrose solutions, drinking water, and running in a wheel can be considered measures of the strength of responses to perceived stimuli. The sucrose study indicates that the strength of the instrumental barpress response was quantitatively related in a correlational sense to the strength of the response to the perceived reinforcer used to establish the instrumental response. The water and activity wheel study indicates that the strength of a response to a perceived stimulus is related to whether this stimulus can serve as a reinforcer for an instrumental response. The two studies taken together, along with other research by Premack, strongly suggest that the customary effects of reinforcers and deprivation level on the strength of instrumental responses are quantitatively related to the effects of these independent variables on the strength of responses to the perceived reinforcers employed to establish instrumental responses.

\section{LEARNED RESPONSES AND RESPONSES TO PERCEIVED REINFORCERS}

Learning psychologists have not frequently talked in terms of the strength of response to a perceived reinforcer. It is a measure of responding that occurs while a reinforcer is and can be perceived. In Premack's work, the measure of strength of response to a perceived reinforcer often is the proportion of time an animal will perceive the reinforcer, as in the studies described above. UCR strength is a measure of responding that occurs while a UCS (reinforcer) occurs, and therefore it is also a measure of the strength of response to a perceived reinforcer.

Premack's work suggests that in general the strength of an instrumental response is quantitatively related to the strength of the response to the perceived reinforcer establishing the instrumental response. The first section indicated that $\mathrm{CR}$ strength is quantitatively related to UCR strength. Because UCR strength is a measure of the strength of response to a perceived reinforcer, it follows that for both classical and instrumental conditioning the strength of a learned response is quantitatively related to the strength of the response to the perceived reinforcer used to establish the learned response.

Both the CR and the instrumental response are related to the response elicited by the perceived reinforcers establishing these learned responses in a qualitative way as well as a quantitative way. The CR is obviously similar to the UCR in respect to response topography. The instrumental response is qualitatively related to the response to the perceived reinforcer establishing it in the sense that the instrumental response allows an animal to perceive the reinforcer and measures of the responses to a perceived reinforcer used in Premack's work, e.g.; the proportion of time a reinforcer is perceived, involve allowing an animal to perceive the reinforcer.

Gray (1975) and the author independently recognized that both CR strength and the strength of the instrumental response may be related to "animal's responses to reinforcing stimuli" (p. 193). Gray indicated that the effect of deprivation of reinforcers on CR strength is related to the effect of this factor on UCR strength; that the effects of deprivation of reinforcers and amount, intensity, and quality of reinforcers on instrumental response strength are related to the effects of these factors on Premack's measures of the strength of responding to reinforcing stimuli; and that UCR strength and the justmentioned measures of Premack are both measures of responses to reinforcers. However, it was only implicitly indicated that the effects of the amount and intensity of the UCS on CR strength and UCR strength are related. In addition, apparently the only direct evidence for a positive relation between CR strength and UCR strength mentioned by Gray is the DeBold et al. (1965) study. Gray thought of the relation between learned response strength and strength of responses to perceived reinforcers as superseding the drive and incentive ideas of Hull and other stimulus-response oriented theorists, as does the author. But Gray made no indication of an interpretation of a relation between learned and perceived reinforcer response strengths in terms of images, as does the author (below). In addition, Gray writes that "Premack appears to be saying that the probability of the reinforcing activity must be high at the instant when it is used as a reinforcer" (p. 214, his italics) and then refers to this idea as tautological, when, in fact, it is a further indication (assuming Premack is correct) of the close correspondence between learned responses and responses to perceived reinforcers.

\section{IMAGES, PERCEIVED STIMULI, LEARNED RESPONSES, AND RESPONSES TO PERCEIVED REINFORCERS}

It has just been concluded that the learned response is qualitatively and quantitatively related to the response to the perceived reinforcer establishing it. It will also be concluded, and this conclusion will be supported in the last two sections of the paper, that effects of images of stimuli on responding are qualitatively and quantitatively related to the effects of perceived stimuli on responding. The conclusion involving learned responses and responses to perceived reinforcers is analogous to the conclusion involving images of stimuli and perceived stimuli and their effects on responding in three respects.

The first respect is that for both conclusions a qualitative and quantitative relation exists between two factors. The second respect is that the two conclusions 
both involve responses to perceived stimuli. The third respect is that the two conclusions both involve responses that are not due to perceived stimuli; by definition learned responding excludes contribution to this responding by the reinforcer (this statement would be modified slightly for some types of instrumental conditioning other than reward learning), and by definition the effect of an image on responding excludes contribution to this responding by the corresponding real stimulus.

The described analogy between the two conclusions supports a further possibility, that learned responses are due at least in part to images of reinforcers. In other words, it may be that while an animal has not yet executed the learned response an image of the reinforcer occurs and that the learned response results, in part, from an image of this reinforcer. The reason that the learned response is qualitatively and quantitatively related to the response to the perceived reinforcer establishing the learned response would then be that an image of the reinforcer results in learned responding that is qualitatively and quantitatively related to the response to the perceived reinforcer. That is, the reason that the learned response is qualitatively and quantitatively related to the response to the perceived reinforcer may be that this outcome is an instance of the general finding that effects of images of stimuli on responding are qualitatively and quantitatively related to the effects of perceived stimuli on responding.

\section{IMAGE-PRODUCED AND STIMULUS-PRODUCED EFFECTS}

It was assumed above that the effects of real stimuli and images of these stimuli on responses are qualitatively and quantitatively related. That images of stimuli affect responding much as real stimuli do can no longer be in doubt. A brief, incomplete indication of studies supporting this statement appears in this and the next section.

Segal and Fusella (1970) found that images of auditory stimuli (more correctly, requests to imagine such stimuli) interfered more with detection of auditory stimuli than did images of visual stimuli and that images of visual stimuli interfered more with detection of visual stimuli than did images of auditory stimuli. Moyer (1973) presented pairs of names of different animals to subjects, and they were required to indicate the larger animal. The choice reaction time increased as the difference between the ranked sizes of the pairs of named animals increased. Presumably, the comparison of size process was mediated by images of the named animals occurring, with reaction time affected just as reaction time is affected by the extent of similarity between pairs of real stimuli. Shepard and Metzler (1971) found that the time required for subjects to decide whether two visually presented forms could be made congruent increased linearly with an increase in the number of degrees of rotation that would be required to actually rotate these forms to determine if congruence would occur. Imagining a component line of the Poggendorff illusion led to as large an illusion as presentation of the real component line (Pressey \& Wilson, 1974). Imagining a tone repeatedly led to greater subsequent habituation to repeated presentations of this tone than imagining a light repeatedly (Yaremko, Glanville, \& Leckart, 1972).

\section{SPECIFIC EFFECTS OF IMAGES AND CONDITIONING}

It has been reasoned at a general level that the learned response is due, in part, to an image of its reinforcer. A remaining task is to relate specific ways in which images of stimuli affect responding to performance of the CR and instrumental response.

Another similarity between the effects of images of stimuli and the effects of real stimuli is that images of stimuli (more correctly, requests to imagine stimuli) result in reponses similar to those produced by the corresponding real stimuli. Strong support for this conclusion was summarized by King (1973). An example of the supporting evidence is that when we imagine food we salivate, salivation obviously also being the response made to perceived food. Surprisingly, other treatments of images and image theories of learning (Hebb, 1968; Konorski, 1967; Paivio, 1971; Richardson, 1969; Segal, 1971) do not mention that image-produced responses resemble stimulus-produced responses.

That image-produced responses are similar to stimulus-produced responses leads directly to an explanation of the CR. King (1973) proposed that the CS results in an image of the UCS and therefore the CR occurs. This theory makes sense. For example, for salivary conditioning, the CS produces an image of food and salivation thereby occurs, just as salivation occurs when we imagine food. Konorski (1967) also assumed that the CR results from a CS-produced image of the UCS, but he did not back up this hypothesis by citing the evidence indicating that image-produced responses are related to stimulus-produced ones.

Evidence suggests that humans tend to bring about and maintain an image of a stimulus that, if it were real, would be approached and continued to be perceived. Atkinson and McClelland (1948) and Sanford (1937) found that food-deprived subjects were more likely to include food-related themes in their responses to TATlike pictures than were subjects not deprived of food. Because food-related themes may be positively related to occurrences of images of food, these studies suggest that deprivation of food increased the tendency to bring about and maintain images of food. Increased deprivation of food obviously increases the extent to which real food is approached and continued to be perceived.

If humans behave so as to bring about images of posi- 
tive reinforcers, as the above discussion suggests, perhaps it is because images of positive reinforcers function as goals for instrumental-like responding, related, of course, to real positive reinforcers establishing instrumental conditioning. In fact, subjects have been requested to imagine reinforcers after exhibiting or imagining certain behaviors, and positive relations between behavior change scores and indications of vividness of the images of the reinforcers have been obtained (Janda \& Rimm, 1972; Tondo \& Cautela, 1974). For example, Tondo and Cautela asked subjects to imagine a highly pleasant scene each time they overestimated the size of a circle. Subjects with vivid imagery, as measured by a self-report scale, increased their estimation of the size of circles, while subjects with faint imagery did not. The obtained results of these studies can be interpreted as suggesting that if an image of a reinforcer is sufficiently vivid it may establish instrumental-like responding.

In accord with the discussion of the previous two paragraphs is King's (1974) proposal that in instrumental conditioning animals behave so as to bring about more vivid images of goal stimuli. It was reasoned that to do this they bring about response-produced stimuli that increasingly approximate the stimulus produced by the instrumental response and thereby execute this response. The King paper may be consulted for additional description of the theory and discussion of related theories.

\section{REFERENCES}

Atrinson, J. W., \& McClelland, D. C. The projective expression of needs: II. The effect of different intensities of the hunger drive on thematic apperception. Journal of Experimental Psychology, 1948, 38, 643-658.

DeBold, R. C., Miller, N. E., \& Jensen, D. D. Effect of strength of drive determined by a new technique for appetitive classical conditioning of rats. Journal of Comparative and Physiological Psychology, 1965, 59, 102-108.

Finch. G. Hunger as a determinant of conditional and unconditional salivary response magnitude. American Journal of Physiology, 1938, 123, 379-382.

Gray, J. A. Elements of a two-process theory of learning. London: Academic Press. 1975.

HebB, D. O. Concerning imagery. Psychological Review, $1968,75,466-477$.

Holland, P. C., \& Rescorla, R. A. The effect of two ways of devaluing the unconditioned stimulus after first-and secondorder appetitive conditioning. Animal Behavior Processes, 1975, 1, 355-363.

JANDA, L. H., \& Rimm, D. C. Covert sensitization in the treatment of obesity. Journal of Abnormal Psychology, 1972, 80. $37-42$.
King, D. L. An image theory of classical conditioning. Psychological Reports, 1973, 33, 403-411.

KING, D. L. An image theory of instrumental conditioning. Psychological Reports, 1974, 35, 1115-1122.

KonORSKI. J. Integrative activity of the brain. Chicago: University of Chicago Press, 1967.

Mitchell, D. S., \& Gormezano, I. Effects of water deprivation on classical appetitive conditioning of the rabbit's jaw movement response. Learning and Motivation, 1970, 1, 199-206.

MOYER, R. S. Comparing objects in memory: Evidence suggesting an internal psychophysics. Perception \& Psychophysics. 1973, 13. 180-184.

Öman, A., Björkstrand, P., \& Ellström, P. Effect of explicit trial-by-trial information about shock probability in long interstimulus interval GSR conditioning. Journal of Experimental Psychology. 1973, 98, 145-151.

Paivio, A. Imagery and verbal processes. New York: Holt. Rinehart and Winston, 1971.

Pavlov, I. P. Conditioned reflexes. London: Oxford University Press, 1927.

Premack, D. Prediction of the comparative reinforcement values of running and drinking. Science, 1963, 139, 1062-1063.

Premack. D. Reinforcement theory. In D. Levine (Ed.). Nebraska symposium on motivation. Lincoln, Nebraska: University of Nebraska Press, 1965.

Pressey, A. W., \& Wilson, A. E. The Poggendorff illusion in imagination. Bulletin of the Psychonomic Society, 1974, 3. 447-449.

Rescorla, R. A. Effect of US habituation following conditioning. Journal of Comparative and Physiological Psychology, 1973, 82, 137-143.

Richardson, A. Mental imagery. New York: Springer, 1969.

SANFORD, R. N. The effects of abstinence from food upon imaginal processes: A further experiment. Journal of Psychology, 1937, 3, 145-159.

SEGAL. S. J. (Ed.). Imageñ: Current cognitive approaches. New York: Academic Press. 1971.

SEGAL. S. J., \& Fusella. V. Influence of imaged pictures and sounds on detection of auditory and visual signals. Journal of Experimental Psychology, 1970, 83, 458-464.

Sheafor, P. J., \& Gormezano, I. Conditioning the rabbit's (Oryctolagus cuniculus) jaw-movement response: US magnitude effects on URs, CRs, and pseudo-CRs. Journal of Comparative and Physiological Psychology, 1972, 81, 449-456.

Shepard, R. N., \& METzLer, J. Mental rotation of threedimensional objects. Science, 1971, 171, 701-703.

TAYLOR, J. A. Level of conditioning and intensity of the adaptation stimulus. Journal of Experimental Psychology, 1956, 51, 127-130.

Tondo, T. R., \& CAUtela, J. R. Assessment of imagery in covert reinforcement. Psychological Reports, 1974, 34, $1271-1280$.

YAREMKo, R. M., Glanville, B. B., \& LeCkART, B. I. Imagerymediated habituation of the orienting reflex. Psychonomic Science, 1972, 27, 204-206.

(Received for publication January 22, 1976.) 